УДК 551.35

\title{
ИССЛЕДОВАНИЕ СОСТАВА ОРГАНИЧЕСКОГО ВЕЩЕСТВА ДОННЫХ ОСАДКОВ MOРЯ ЛАПТЕВЫХ С ПРИМЕНЕНИЕМ MЕТОДА ROCK-EVAL
}

\author{
Гершелис Елена Владимировна', \\ elenapanova@tpu.ru
}

\author{
Кашапов Роман Сергеевич1, \\ kashapovrs@yandex.ru
}

Рубан Алексей Сергеевич1,
ruban@tpu.ru
Оберемок Ирина Андреевна 1 , genuine.i@yandex.ru

\author{
Леонов Андрей Андреевич1,2, \\ laa91@tpu.ru
}

\author{
Черных Денис Вячеславович³, \\ denis.chernykh.vl@gmail.com
}

Дударев Олег Викторович³,
dudarev@poi.dvo.ru

Семилетов Игорь Петрович 3,1 ,
ipsemiletov@alaska.edu

1 Национальный исследовательский Томский политехнический университет,

Россия, 634050, г. Томск, пр. Ленина, 30.

2 Институт сильноточной электроники СО РАН,

Россия, 634055, г. Томск, пр. Академический, 2/3.

3 Тихоокеанский океанологический институт им. В.И. Ильичева ДВО РАН, Россия, 690041, г. Владивосток, ул. Балтийская, 43.

\begin{abstract}
Актуальность исследования обусловлена необходимостью всестороннего изучения процессов, ответственных за изменения биогеохимического режима арктического региона. Увеличение темпов деградации прибрежной и подводной мерзлоты на Восточно-Сибирском шельфре приводит к вовлечению в современный биогеохимический цикл большого объема ремобилизованного органического углерода. Изучение особенностей его транспорта и преобразования в системе суша-шельфф играет важную роль для оценки функционирования крайне хрупкой арктической экосистемы.

Цель: изучение геохимических характеристик органического вещества, прослеживаемых по профилю от береговой зоны к континентальному склону моря Лаптевых с применением метода Rock-Eval и оценка их взаимосвязи с литологическими свойствами вмещающих осадков.

Объектом исследования явились пробы донных осадков, взятые с поверхностного горизонта (0-2 см). Отбор проб проводился в морских арктических экспедициях 2018-2019 г2. на НИС «Академик Мстислав Келдьш».

Результаты. На основе результатов пиролитического анализа дана геохимическая характеристика органического вещества, содержащегося в донных осадках моря Лаптевых. Органическое вещество, экспортируемое с речным стоком и продуктами береговой эрозии, характеризуется относительно низким кислородным (OI) и водородным (HI) индексами в прибрежной зоне и на глубинах до нескольких десятков метров. В районе среднего шельфа существенное влияние на состав органического вещества, по всей видимости, оказывает снос осадочного вещества с Новосибирских островов, где активно действуют термоабразионные процессы (снижение значений HI и увеличение ОІ). Высказано предположение, что для продуктов, выносимых речным стоком, и продуктов эрозии берегов характерны различные пиролитические параметры, определяемые методом Rock-Eval (в частности, значения HI, Ol и Tpeak).
\end{abstract}

\section{Ключевые слова:}

Пиролиз, доннье осадки, органическое вещество, углеводороды, Арктика, море Лаптевых.

\section{Введение}

Возрастающие темпы деградации прибрежной мерзлоты на Восточно-Сибирском арктическом шельфе провоцируют активное высвобождение и экспорт больших объемов наземного органического углерода (ОУ), вовлекающихся в современный биогеохимический цикл. По предварительным оценкам только в результате береговой эрозии на ВосточноСибирский арктический шельф экспортируется порядка $44 \pm 10$ Мт наземного ОУ [1]. Поступающий на шельф ОУ может быть окислен до $\mathrm{CO}_{2}$, перенесен в глубокую часть Северного Ледовитого океана или сохранен в донных осадках вместе с автохтонным органическим материалом. Усиление роли наземного углерода в арктической экосистеме может привести не только к изменению биогеохимического и седиментационного режимов арктических морей, но так- же и к серьезным экологическим последствиям (смещение карбонатного равновесия, асидификация вод, рост эмиссии парниковых газов) [2-4]. Достоверное установление источников ОУ и исследование механизмов его трансформации в системе суша-шельф является важной задачей для формирования объективной оценки баланса углерода в северных широтах.

В последние годы особое внимание уделялось исследованию природы органического вещества (OB), хранящегося в донных осадках арктических морей, на молекулярном уровне с использованием биомаркеров. В настоящей работе мы впервые применяем метод Rock-Eval для установления особенностей состава OB современных донных осадков на обширной акватории шельфа моря Лаптевых. Пиролитический анализ Rock-Eval - традиционный метод в нефтяной геологии, используемый для оценки нефтегенерационного 
потенциала осадочных пород [5-8]. Тем не менее в настоящее время он все чаще используется и для исследований органической компоненты почв и современных осадков [9-14]. В приведенных работах показано, что с помощью пиролитического анализа незрелого органического материала можно получить данные о доле морского и терригенного ОВ и степени его диагенетической преобразованности. Пиролиз RockEval может служить дополнительным инструментом, эффективно дополняющим традиционные геохимические методы исследования ОВ, основанные на изучении его элементного, молекулярного и изотопного состава.

\section{Материалы и методы исследований}

Район исследования

Восточно-Сибирский арктический шельф, самый широкий и мелководный континентальный шельф Мирового океана, при средней глубине порядка $50 \mathrm{M}$ занимает $2,1 \times 10^{6} \mathrm{Kм}^{2}$ и охватывает море Лаптевых, Восточно-Сибирское море и российскую часть Чукотского моря. Самое мелководное море арктического шельфа, море Лаптевых, представляет собой уникальный интегратор наземного биогеохимического сигнала, поступающего вместе с продуктами интенсивной береговой эрозии и речным стоком реки Лены. Достоверно установлено, что именно дестабилизация мощного берегового ледового комплекса (Едома) является доминирующим источником наземного органического углерода на шельфе моря Лаптевых. Общий вклад продуктов интенсивной эрозии берегов в бассейн моря Лаптевых и Восточно-Сибирского моря оценивается в пределах 4,0-22 \pm 8 Тг/год (с учетом дестабилизации подводной мерзлоты) $[1,15,16]$.

Механизмы переноса осадочного материала зависят преимущественно от атмосферных условий: циклоническая циркуляция поверхностных вод обеспечивает прибрежный поток, движущийся с запада на восток и усиливающийся с ленским течением; в период развития антициклонического режима ось трансарктического течения смещается к материковому склону Евразии, воздушные массы переносятся на север и в этом же направлении усиливается транспорт воды и льдов [17].

По разным оценкам, скорости осадконакопления на шельфе моря Лаптевых в голоцене варьируются между 0,12 и 0,59 мм/год согласно результатам радиоуглеродного датирования морских двустворчатых моллюсков [18], тогда как по данным радиоизотопного датирования (метод свинца-210) скорости современного осадконакопления могут достигать 1,3 мм/год [1].

В настоящей работе мы предприняли попытку оценить изменчивость качественного и количественного состава ОВ с привлечением пиролитического анализа по профилю прибрежная зона - средний шельф.

\section{Фактический материал}

Данное исследование основано на изучении 16 проб осадков, отобранных во время комплексных арктических морских экспедиций на НИС «Академик Мстислав Келдыш» (2018 г., 73 рейс; 2019 год, 78 рейс; рис. 1). Для отбора образцов кернов осадков использовался коробчатый бокс-корер. Образцы осадков сразу после отбора были перемещены в пластиковые пакеты и далее хранились в холодильнике при температуре $20{ }^{\circ} \mathrm{C}$. Для настоящего исследования использовались образцы, взятые с поверхности (горизонт 0-2 см; для станций 6505 и 6527 - горизонт 0-5 см).

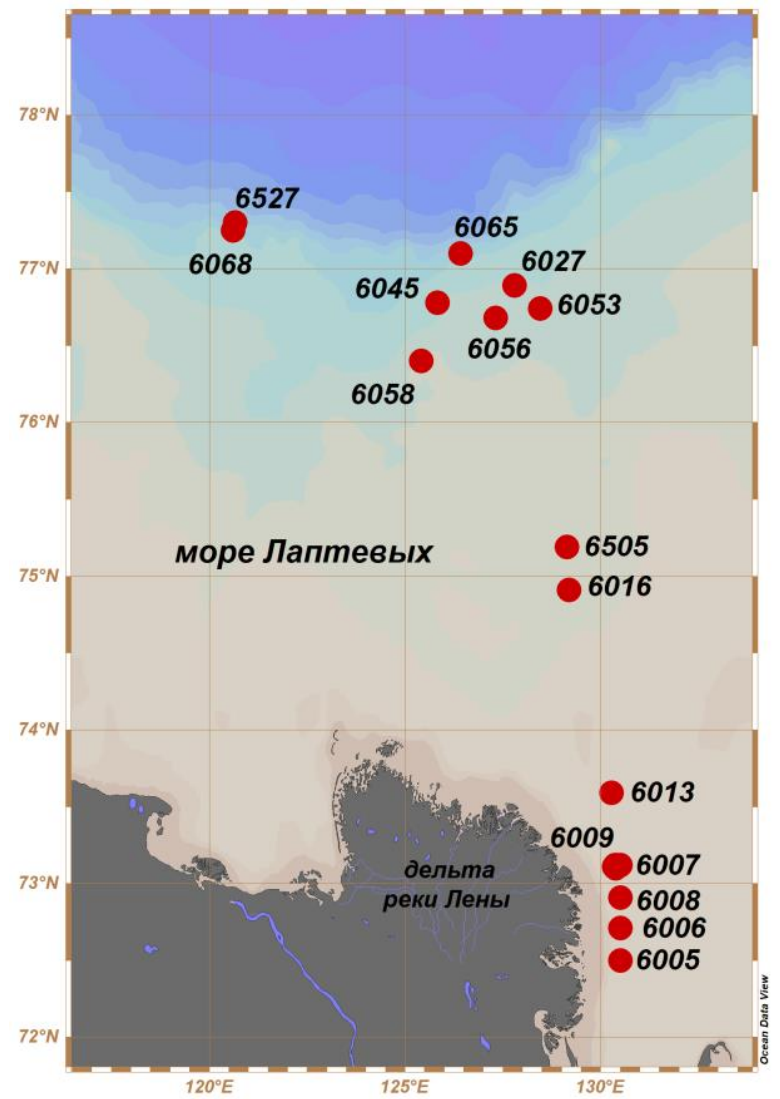

Рис. 1. Расположение станций отбора проб. Станциии с индексом «60...»-рейс № 73, 2018 г.; станции с индексом «65 ...»- - рейс № 78, 2019 г.

Fig. 1. Sampling stations. Stations indexed as «60...» were performed during the $73^{\text {th }}$ cruise, 2018; «65...»during the $78^{\text {th }}$ cruise, 2019

\section{Методы исследования}

Работы выполнялись с использованием пиролитического метода Rock-Eval. Анализ проводился на прибope Rock-Eval 6 Turbo компании Vinci Technologies в Международной научно-образовательной лаборатории изучения углерода арктических морей ТПУ.

Пробы были разморожены и высушены при комнатной температуре в течение суток. Далее часть проб была отобрана для гранулометрического анализа, часть гомогенизирована в фарфоровой ступке и направлена на пиролитические исследования.

Навеска породы массой около 40 мг анализировалась в температурном цикле «Reservoir». Особенность этого цикла заключается в низкой начальной температуре пиролиза. Она составляет $180{ }^{\circ} \mathrm{C}$, и порода выдерживается при ней 10 минут (табл. 1). В течение этого времени высвободившиеся углеводороды током инертного газа подаются в пламенно-ионизационный 
детектор и таким образом формируется пик $\mathrm{S}_{1 \mathrm{r}}$ (мг УВ/г) Дальнейший нагрев от 180 до $650{ }^{\circ} \mathrm{C}$ позволяет получить двойной пик $\mathrm{S}_{2 \mathrm{a}}$ (мг УВ/г) и $\mathrm{S}_{2 \mathrm{~b}}($ мг $\mathrm{УB} / \mathrm{r})$. Пики $S_{1 \mathrm{r}}$ и $\mathrm{S}_{2 \mathrm{a}}$ соответствуют термическому испарению легких и тяжелых углеводородов. Пик $\mathrm{S}_{2 \mathrm{~b}}$ соответствует крекингу геополимеров (рис. 2). Однако если анализируемая порода содержит включения углистого детрита или другого нерастворимого органического вещества, то продукты их деструкции будут накладываться на пик $\mathrm{S}_{2 \mathrm{~b}}$, так как их пиролиз проходит в одном температурном интервале. Температура, соответствующая максимальной скорости выделения углеводородов при формировании пика $S_{2 b}$, обозначена как $\mathrm{T}_{\text {peak }}\left({ }^{\circ} \mathrm{C}\right)$.

Помимо печи пиролиза прибор Rock-Eval 6 Turbo оснащен печью окисления и двумя инфракрасными ячейками для регистрации выделяющихся в ходе пиролиза и окисления газов $\mathrm{CO}$ и $\mathrm{CO}_{2}$. Регистрация $\mathrm{CO}$ и $\mathrm{CO}_{2}$ на стадии пиролиза в режиме реального времени позволяет получить информацию о степени окисленности органического вещества (пик $\mathrm{S} 3$, мг $\mathrm{CO}_{2} / \Gamma$ породы).

На основе определяемых значений параметров пиролиза $\left(\mathrm{S}_{1 \mathrm{r}}, \mathrm{S}_{2 \mathrm{a}}\right.$ и др.) происходит расчет значений пиролизуемого органического углерода (PC, мас. \%).

Дополнительная стадия окисления позволяет рассчитать значения водородного (НI, мг УВ/г $\mathrm{C}_{\text {орг }}$ ) и кислородного (OI, мг $\mathrm{CO}_{2} /$ г $\mathrm{C}_{\text {орг }}$ ) индексов, остаточное содержание органического углерода (RC, мас. \%), полное содержание органического (ТОС, мас. \%) и минерального углерода (MinC, мac. \%) в породе.

Для сопоставимости полученных результатов с опубликованными исследованиями было решено выделить ключевые параметры в следующем виде: $\mathrm{S} 1=\mathrm{S} 1_{\mathrm{r}}+\mathrm{S} 2_{\mathrm{a}}$ и $\mathrm{S} 2=\mathrm{S} 2_{\mathrm{b}}[10,18,19]$.

Tаблица 1. Температурные условия цикла Reservoir

Table 1. Temperature mode for the "Reservoir» cycle

\begin{tabular}{|c|c|c|c|c|c|}
\hline $\begin{array}{c}\text { Стадия } \\
\text { Stage }\end{array}$ & $\begin{array}{c}\text { температура, }{ }^{\circ} \mathrm{C} \\
\text { Initial temperature, } \\
{ }^{\circ} \mathrm{C}\end{array}$ & $\begin{array}{c}\text { Качаленечая } \\
\text { температура, }{ }^{\circ} \mathrm{C} \\
\text { Final temperature, } \\
{ }^{\circ} \mathrm{C}\end{array}$ & $\begin{array}{c}\text { Скорость } \\
\text { нагрева, }{ }^{\circ} \mathrm{C} / \text { мин } \\
\text { Heating rate, } \\
{ }^{\circ} \mathrm{C} / \mathrm{min}\end{array}$ & $\begin{array}{c}\text { Выдержка при начальной } \\
\text { температуре, мин } \\
\text { Exposure at initial } \\
\text { temperature, min }\end{array}$ & $\begin{array}{c}\text { Выдержка при конечной } \\
\text { температуре, мин } \\
\text { Exposure at final } \\
\text { temperature, min }\end{array}$ \\
\hline $\begin{array}{c}\text { Пиролиз } \\
\text { Ругоlisis }\end{array}$ & 180 & 650 & 25 & 10 & 0 \\
\hline $\begin{array}{c}\text { Окисление } \\
\text { Охіdation }\end{array}$ & 300 & 850 & 20 & 1 & 5 \\
\hline
\end{tabular}

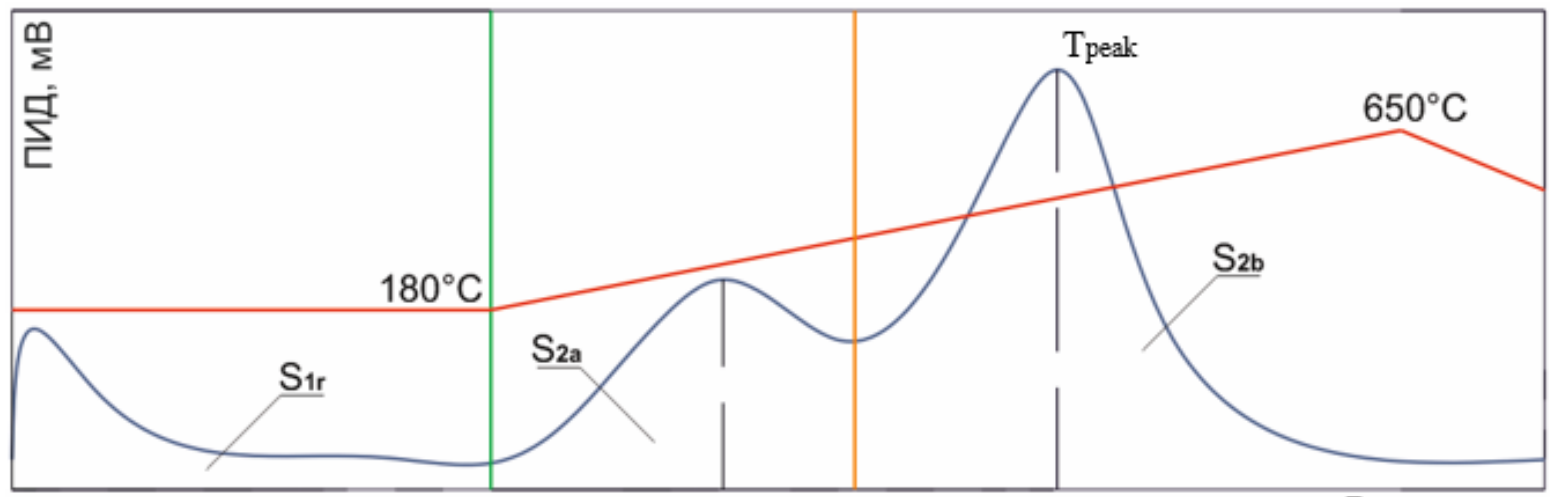

Время, мин

Pис. 2. График пиролиза в ичикле «Reservoir»

Fig. 2. Pyrogram for the "Reservoir» cycle

Гранулометрический состав был определен с помощью лазерной дифракции с применением аппаратного комплекса SALD-7101 («Shimadzu»). При проведении анализа навеска исследуемой пробы помещалась в ванну смесителя с дистиллированной водой и диспергировалась при помощи ультразвуковой установки (40 Вт, 40 кГц). Измерения выполнялись в проточной ячейке.

\section{Результаты и обсуждение}

Содержание ТОС в исследуемых образцах варьируется в пределах от 0,4 до $2,73 \%$, что соотносится с результатами предыдущих исследований в данном регионе [20]. Доля пиролизуемого углерода в общем объеме ТОС составляет от 20 до 30 \% (табл. 1). Традиционное графическое отображение данных пиролиза Rock-Eval представлено на рис. 2. Подобная интерпретация проведена на основе классификации керогена по типу исходного ОВ на основе соотношений $\mathrm{O} / \mathrm{C}$ и $\mathrm{H} / \mathrm{C}$ [9], применяемого при оценке нефтегенерационного потенциала материнских пород. Значения НІ лежат в пределах 100-200 НС мг/г ТОС, при этом значения ОI находятся в диапазоне $180-310 \mathrm{CO}_{2} \mathrm{M \Gamma} / \Gamma$ TOC. Полученное распределение находится в области доминирования наземного ОВ для современных осадков. Более высокие значения как HI, так и ОI приурочены к районам среднего шельфа (рис. 3). 


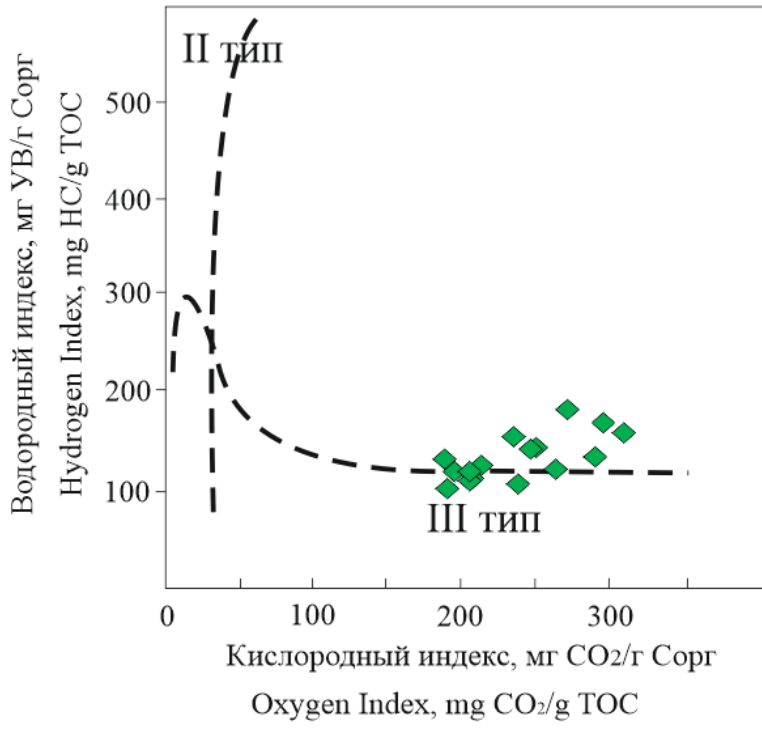

Рис. 3. Модифицированная диаграмма Ван-Кревелена для поверхностных морских осадков шельфа моря Лаптевых

Fig. 3. Modified Van Krevelen-type diagram of surface sediments across the Laptev Sea shelf
Значения $\mathrm{T}_{\text {peak }}$ для исследуемых образцов находятся в диапазоне $380-464{ }^{\circ} \mathrm{C}$. При сопоставлении $\mathrm{T}_{\text {peak }} \mathrm{c}$ параметрами НI и ОI выделяются две группы образцов в температурных интервалах $380-401{ }^{\circ} \mathrm{C}\left(\mathrm{T}_{\text {peak }}\right.$ ср $=382{ }^{\circ} \mathrm{C}$ ) и $448-464{ }^{\circ} \mathrm{C}\left(\mathrm{T}_{\text {peak cp }}=454{ }^{\circ} \mathrm{C}\right.$ ) (рис. 4$) . \mathrm{K}$ высокотемпературному интервалу относятся образцы со средними значениями $\mathrm{OI}_{\mathrm{cp}}=218$ и $\mathrm{HI}_{\mathrm{cp}}=115$, к интервалу более низких температур относятся образцы, где $\mathrm{OI}_{\mathrm{cp}}=270$ и $\mathrm{HI}_{\mathrm{cp}}=152$.

Литологический тип осадков определялся на основе гранулометрического состава (табл. 2) с выделением песчаной (>63 мкм), алевритовой (от 2 до 63 мкм) и пелитовой (<2 мкм) фракций [21-23]. Согласно приведенной трёхкомпонентной классификации исследуемые осадки представлены преимущественно алевритовым материалом (в большинстве образцов его доля составляет $>50$ \%), что в целом соотносится с литологической типизацией осадков для горизонта 2-5 см тех же станций пробоотбора (публикация находится в печати). На станции 6505 отмечается доминирование пелитовой фракции (>50\%). Песчаная фракция в исследованных образцах практически отсутствует; только на станции 6005, расположенной в прибрежной зоне, ее доля составляет более $50 \%$.

Tаблица 2. Параметры Rock-Eval для образиов поверхностных осадков, отобранных на шельфе моря Лаптевых

Table 2. Rock-Eval parameters for Laptev Sea surface sediments

\begin{tabular}{|c|c|c|c|c|c|c|c|c|c|c|c|c|c|}
\hline $\begin{array}{l}\text { Oбразец } \\
\text { Sample }\end{array}$ & $\begin{array}{c}\text { Долгота } \\
\text { Longitude }\end{array}$ & $\begin{array}{l}\text { Широта } \\
\text { Latitude }\end{array}$ & $\begin{array}{c}\text { Глубина, } \\
\text { м } \\
\text { Depth, m }\end{array}$ & Tpeak, ${ }^{\circ} \mathrm{C}$ & $\begin{array}{c}\mathrm{S} 1, \mathrm{Mr} \\
\mathrm{yB} / \mathrm{r} \\
(\mathrm{mg} \\
\mathrm{HC} / \mathrm{g})\end{array}$ & $\begin{array}{c}\mathrm{S} 2, \mathrm{M} \Gamma \\
\mathrm{yB} / \Gamma \\
(\mathrm{mg} \\
\mathrm{HC} / \mathrm{g})\end{array}$ & $\begin{array}{c}\mathrm{S} 3, \\
\mathrm{M \Gamma CO}_{2} / \Gamma \\
\left(\mathrm{mg}^{2}\right. \\
\left.\mathrm{CO}_{2} / \mathrm{g}\right)\end{array}$ & PC (\%) & $\mathrm{RC}(\%)$ & $\operatorname{TOC}(\%)$ & HI & OI & $\operatorname{MinC}(\%)$ \\
\hline 6005 & 130,499 & 72,500 & 14,5 & 461 & 0,37 & 1,78 & 3,02 & 0,28 & 1,14 & 1,42 & 125 & 213 & 0,2 \\
\hline 6006 & 130,499 & 72,707 & 18,5 & 462 & 0,65 & 2,92 & 5,74 & 0,5 & 2,21 & 2,71 & 108 & 212 & 0,4 \\
\hline 6007 & 130,500 & 73,123 & 24,3 & 462 & 0,73 & 2,74 & 5,32 & 0,64 & 2,01 & 2,65 & 103 & 201 & 0,4 \\
\hline 6008 & 130,500 & 72,911 & 22,0 & 462 & 0,71 & 2,61 & 4,82 & 0,48 & 1,79 & 2,27 & 115 & 212 & 0,3 \\
\hline 6009 & 130,374 & 73,115 & 24,0 & 461 & 0,53 & 1,98 & 3,84 & 0,35 & 1,58 & 1,93 & 103 & 199 & 0,3 \\
\hline 6013 & 130,276 & 73,593 & 23,5 & 464 & 0,28 & 1,12 & 1,92 & 0,21 & 0,74 & 0,95 & 118 & 202 & 0,2 \\
\hline 6016 & 129,189 & 74,908 & 40,0 & 459 & 0,39 & 1,52 & 3,38 & 0,37 & 1,01 & 1,38 & 110 & 245 & 0,2 \\
\hline 6027 & 127,797 & 76,892 & 64,0 & 386 & 0,17 & 1,01 & 1,98 & 0,17 & 0,47 & 0,64 & 158 & 309 & 0,2 \\
\hline 6045 & 125,829 & 76,775 & 72,0 & 380 & 0,33 & 1,22 & 1,86 & 0,2 & 0,59 & 0,79 & 154 & 235 & 0,2 \\
\hline 6053 & 128,453 & 76,739 & 65,0 & 390 & 0,34 & 1,52 & 3,32 & 0,28 & 0,98 & 1,26 & 121 & 263 & 0,2 \\
\hline 6056 & 127,317 & 76,679 & 62,0 & 380 & 0,19 & 1 & 1,75 & 0,16 & 0,54 & 0,7 & 143 & 250 & 0,2 \\
\hline 6058 & 125,419 & 76,396 & 52,0 & 369 & 0,11 & 0,87 & 1,3 & 0,13 & 0,35 & 0,48 & 181 & 271 & 0,1 \\
\hline 6065 & 126,424 & 77,103 & 251,0 & 380 & 0,11 & 0,67 & 1,18 & 0,11 & 0,29 & 0,4 & 168 & 295 & 0,1 \\
\hline 6068 & 120,614 & 77,246 & 185 & 401 & 0,19 & 0,92 & 2 & 0,16 & 0,53 & 0,69 & 133 & 290 & 0,2 \\
\hline 6505 & 129,141 & 75,186 & 40,0 & 451 & 0,61 & 1,49 & 2,41 & 0,36 & 0,91 & 1,27 & 117 & 190 & 0,2 \\
\hline 6527 & 120,655 & 77,301 & 375 & 389 & 0,58 & 1,57 & 2,56 & 0,34 & 0,79 & 1,13 & 139 & 227 & 0,2 \\
\hline
\end{tabular}

Расшифровка параметров Tpeak, S1, S2, S3, PC, RC, TOC, HI, OI, МіпC приведена в тексте (раздел «Материаль и методы исследований»).

Parameters Tpeak, S1, S2, S3, PC, RC, TOC, HI, OI, MinC are explained in the text (Section «Materials and methods»).

Параметры, регистрируемые методом Rock-Eval, отражают генетические особенности органического вещества биопродуцентов (морского или терригенного происхождения), а также процессы его преобразования на стадии диа- и катагенеза. В случае донных отложений наиболее информативными параметрами являются S1, S2, S3, RC и Tpeak. Относительно высокие значения S1 и S2 характерны для морской пер- вичной продукции, тогда как в наземном органическом материале отмечается повышение параметра S3 и доли остаточного углерода (RC). Различия обусловлены составом морского органического вещества низкой концентрацией или отсутствием лигнина, кислородсодержащего полимера наземного происхождения, и более высоким содержанием липидов по сравнению с терригенной продукцией. В процессе пере- 
работки и окисления (деградации) ОВ происходит увеличение доли кислородсодержащих соединений и, соответственно, уменьшение содержания водорода, что и отражается в значениях НI и ОI для ОВ различного происхождения и степени преобразованности

ala

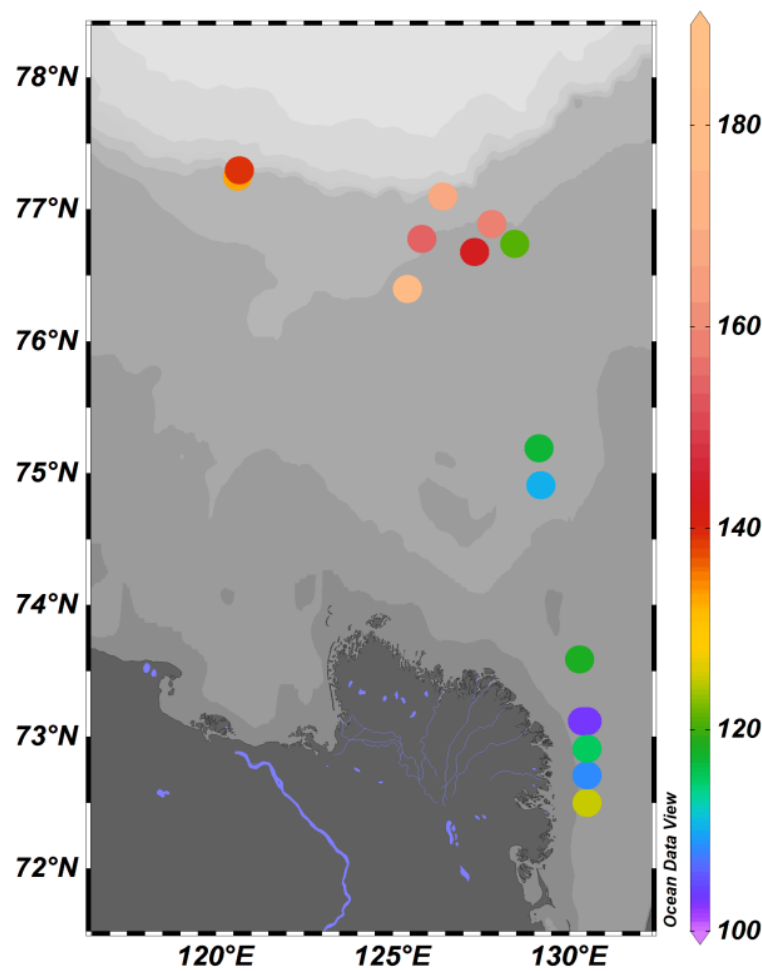

[21]. Таким образом, свежесинтезированное ОВ современных осадков характеризуется высокими значениями параметра HI/OI (>2); тогда как для OB, претерпевшего цикл диагенетических преобразований, значения НI/OI снижаются.

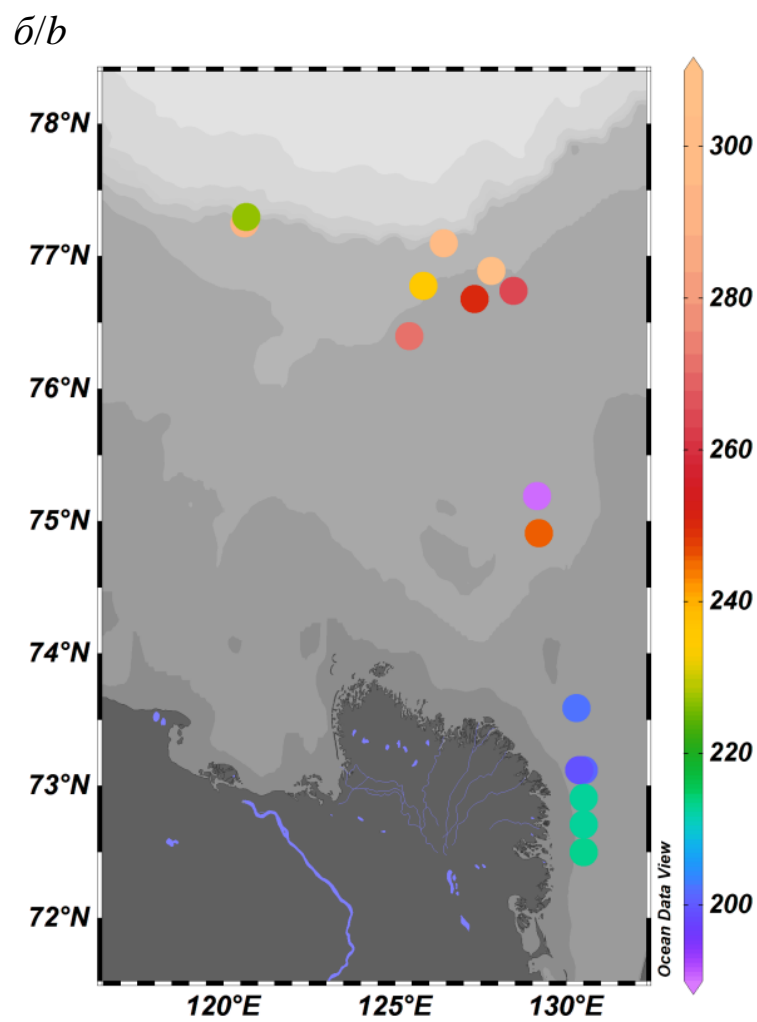

Pис. 4. Значения HI, мг УВ/2 Сорг (а) и ОI, мг $\mathrm{CO}_{2} / 2$ Сорг (б) для поверхностных морских осадков шельфа моря Лаптевых

Fig. 4. $\mathrm{HI}\left(\mathrm{mg} \mathrm{HClg} \mathrm{TOC)} \mathrm{(a)} \mathrm{and} \mathrm{OI}\left(\mathrm{mg} \mathrm{CO}_{2} / g\right.\right.$ TOC) (b) values of surface sediments across the Laptev Sea shelf

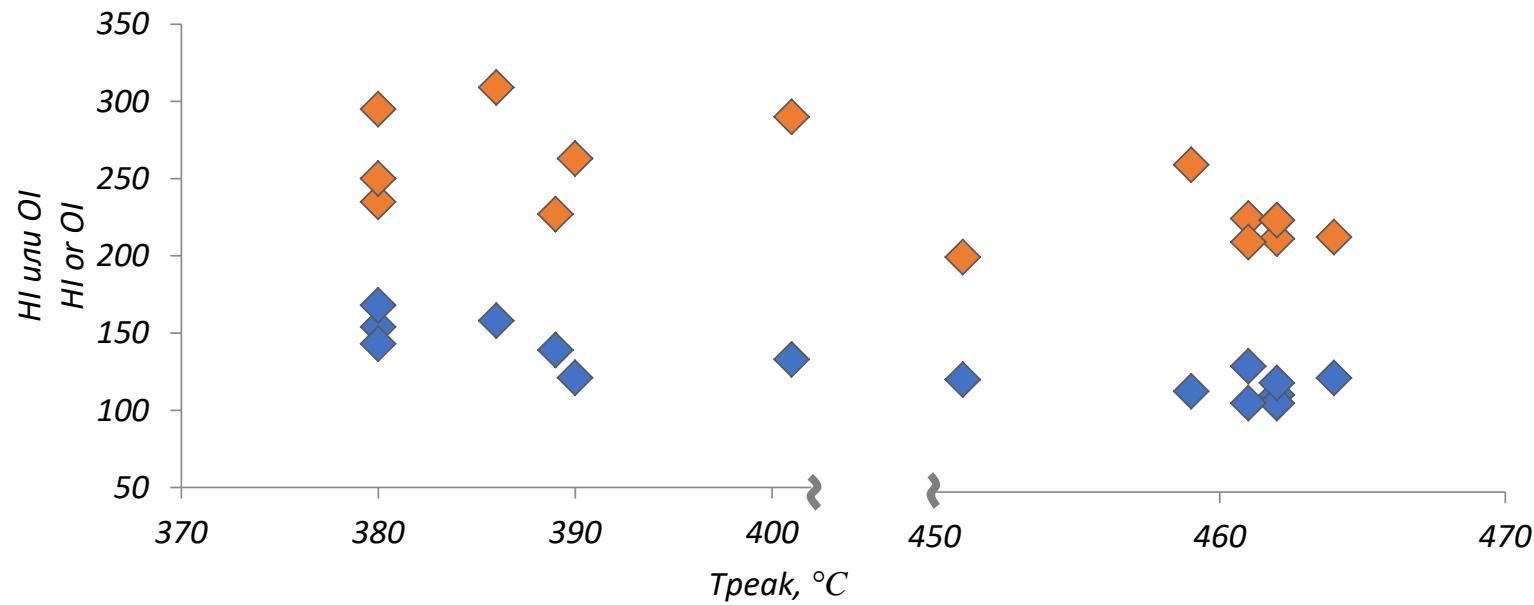

Pис. 5. Взаимосвязь кислородного и водородного индексов (оранжевые и синие ромбы, соответственно) и параметpa Tpeak, ${ }^{\circ} \mathrm{C}$

Fig. 5. Correlation of HI (blue symbols) and OI (orange symbols) and Tpeak, ${ }^{\circ} \mathrm{C}$ 
Так, низкие значения НI, не превышающие 200 УВ мг/г Сорг, вкупе с соотношением $\mathrm{HI} / \mathrm{OI}<1$, указывают на доминирующий вклад наземного ОВ и/или значительную степень диаганетической преобразованности вещества для всех исследованных образцов, охватывающих профиль «прибрежная зона - континентальный склон» [24, 25].

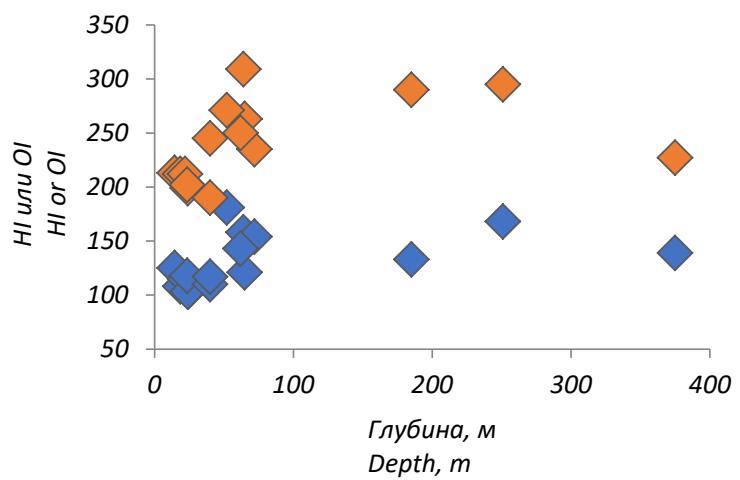

Pис. 6. Взаимосвязь кислородного и водородного индексов (оранжевые и синие ромбы, соответственно) и глубины отбора проб

Fig. 6. Correlation of HI (blue symbols) and OI (orange symbols) and sampling stations depths

По мере удаления от берега в осадках наблюдается ожидаемое уменьшение содержания органического углерода, что отмечалось многочисленными исследователями ранее [1, 2, 18, 21, 26 и др.]. Несмотря на слабую корреляцию между параметрами НI, OI и глубиной станции отбора $\left(\mathrm{R}^{2}<0,2\right)$ (рис. 6), образцы можно условно разделить на две группы: станции 60056016 и 6505 на внутреннем шельфе, где $\mathrm{HI}<130$, и станции 6027-6527 в области внешнего шельфа, где HI $>130$ (за исключением станции 6053). Значение $\mathrm{HI}=130$ мг НС/г ТОС в данном случае может служить порогом перехода от доминирующего вклада наземного ОВ к влиянию первичной продукции. Подобным образом были определены пороговые значения НІ для незрелого ОВ осадков шельфа Карского моря и центральной части Северного Ледовитого океана, а также в осадках Гудзонова залива $[17,21,27]$. В указанных работах пороговое значение НІ составило 100 мг УВ мг/г Сорг. Более низкое значение НІ может быть связано со статистическим фактором: в указанных работах объектами исследований были керны четвертичных отложений, охватывающие глубину до нескольких десятков метров, и объем фактического материала составлял сотни образцов. Наша работа на текущем этапе ограничилась поверхностным горизонтом, но, несомненно, данный подход в дальнейшем будет расширен для большего объема образцов и охвата нижележащих горизонтов.

Предположительно, более высокое пороговое значение НІ может быть обусловлено особенностями состава OB, характерными для биогеохимического режима моря Лаптевых. Необходимо учитывать, что вклад ремобилизованного («древнего») ОВ, экспортируемого с продуктами береговой эрозии, и вклад осадочного вещества, транспортируемого с речным стоком, где большую часть составляет современный органический материал, имеет различные геохимические параметры. По оценкам, приведенным в работе [28], около 60 \% ОВ донных осадков в заливе БуорХая составляет ремобилизованное ОВ ледового комплекса. В предыдущих исследованиях уже было высказано предположение, что в отложениях ледового комплекса могла быть законсервирована свежесинтезированная биомасса, формировавшаяся в короткие вегетативные сезоны [29].

Таблица 3. Гранулометрический состав донных осадков восточной части моря Лаптевых

Table 3. Grain-size characteristics of bottom sediments across the eastern part of the Laptev Sea

\begin{tabular}{|c|c|c|c|c|}
\hline \multirow[t]{2}{*}{$\begin{array}{c}\text { № станции } \\
\text { Sampling } \\
\text { station }\end{array}$} & \multirow[t]{2}{*}{$\begin{array}{c}\text { Глубина, м } \\
\text { Depth, m }\end{array}$} & $\begin{array}{c}\text { Песок } \\
\text { Sand } \\
(>63)\end{array}$ & $\begin{array}{c}\text { Алеврит } \\
\text { Silt } \\
(2-63)\end{array}$ & $\begin{array}{c}\text { Пелит } \\
\text { Clay } \\
(<2) \\
\end{array}$ \\
\hline & & \multicolumn{3}{|c|}{ мКм/ $/ \mu \mathrm{m}$} \\
\hline 6005 & 14,5 & 51,8 & 39,1 & 9,1 \\
\hline 6006 & 18,5 & 0,1 & 69,3 & 30,6 \\
\hline 6007 & 24,3 & 0,0 & 79,3 & 20,7 \\
\hline 6008 & 22 & 0,0 & 73,2 & 26,8 \\
\hline 6009 & 24 & 0,0 & 71,5 & 28,5 \\
\hline 6013 & 23,5 & 0,0 & 76,9 & 23,1 \\
\hline 6016 & 72 & 0,0 & 79,3 & 20,7 \\
\hline 6027 & 64 & 0,0 & 84,0 & 16,0 \\
\hline 6045 & 72 & 1,2 & 86,7 & 12,1 \\
\hline 6053 & 65 & 0,4 & 83,6 & 16,0 \\
\hline 6056 & 62 & 0,2 & 71 & 28,8 \\
\hline 6058 & 52 & 7,7 & 80 & 12,3 \\
\hline 6065 & 251 & 2,4 & 82,1 & 15,5 \\
\hline 6068 & 185 & 0,0 & 84,8 & 15,2 \\
\hline 6505 & 40 & 5,9 & 32,1 & 62,0 \\
\hline 6527 & 375 & 0,0 & 73,1 & 26,9 \\
\hline
\end{tabular}

Значения ОI варьируются в более широких пределах. Параметр может отражать как экспорт уже окисленного ОВ с речным стоком и продуктами береговой эрозии, так и последующую деградацию аллохтонного и автохтонного ОВ в водной толще и по мере захоронения в осадках, поэтому важной задачей представляется разделение этих двух процессов.

Интерпретация значений Tpeak основана на термической стабильности различных органических соединений, присутствующих в осадочном веществе. Так, низкие температуры, как правило, характерны для свежесинтезированного ОВ, в том числе биомакромолекул, таких как целлюлоза и лигнин [9]; углеводородов морского ОВ [24]; низкие значения Tpeak также фиксируются при высоком содержании дезоксисахаров, образующихся в процессе активного микробиального окисления во взвешенном ОВ [30]. Отметим, что для станций 6505 и 6016, находящихся в зоне сноса осадочного материала с близлежащих Новосибирских островов, ремобилизованного в результате береговой эрозии, характерны высокие значения Tpeak и повышение значений OI. При этом для станций, расположенных на внешнем шельфе, средняя величина Tpeak снижается, а диапазон значений OI остаётся прежним. Картина в прибрежной зоне отличается: здесь при сохранении высоких значениях Tpeak кислородный индекс в среднем на несколько 
десятков ниже, чем для районов среднего шельфа. Предварительно можно сделать предположение, что снос эрозионного материала прослеживается повышенным индексом OI и более высоким значением Tpeak, однако эта гипотеза требует подтверждения на большем объёме фактического материала.

Положительная корреляция между долей пелитовой фракции и содержанием кислородсодержащих структур OB (S3) дает основание предположить, что повторяющееся ресуспендирование осадка (главным образом, дисперсной фракции) регулярно подвергает окислению ассоциированное с матрицей зерен ОВ. В таком случае роль минеральной матрицы как фактора, препятствующего деградации ОВ в процессе переноса, может быть снижена, что было ранее отмечено и для осадков Гудзонова залива [27].

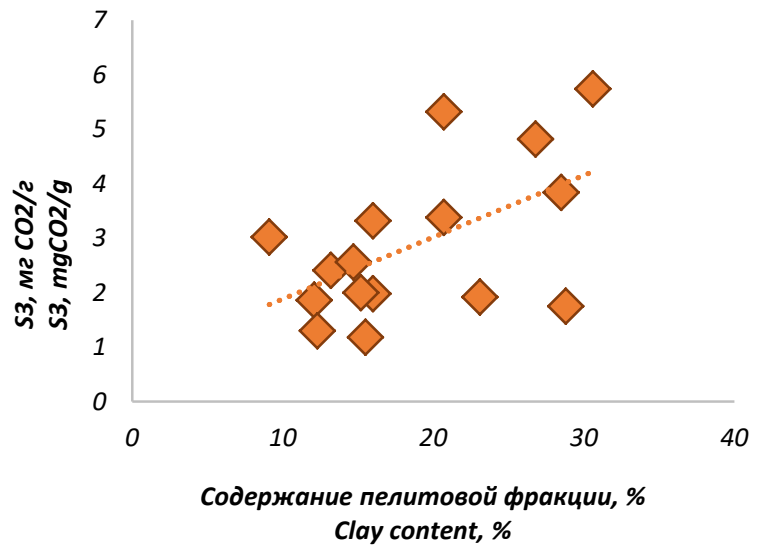

Pис. 7. Взаимосвязь параметра $\mathrm{S} 3\left(\right.$ мгCO$\left._{2} / 2\right)$ и доли пелитовой фракции в осадках

Fig. 7. Correlation of $\mathrm{S} 3\left(\mathrm{mgCO}_{2} / \mathrm{g}\right)$ and the fraction of clay particles in surface sediments

\section{Заключение}

В рамках данной работы показано, что содержание органического углерода (Total organic carbon, TOC) в

\section{СПИСОК ЛИТЕРАТУРЫ}

1. Activation of old carbon by erosion of coastal and subsea permafros in Arctic Siberia / J.E. Vonk, L. Sánchez-García, B.E. van Dongen, V. Alling, D. Kosmach, A. Charkin, I.P. Semiletov, O.V. Dudarev, N.E. Shakhova, P. Roos, T.I. Eglinton, A. Andersson, Ö. Gustafsson // Nature. - 2017. - V. 489. - P. 137-140.

2. Acidification of East Siberian Arctic Shelf waters through addit ion of freshwater and terrestrial carbon / I. Semiletov, I. Pipko, Ö. Gustafsson, L.G. Anderson, V. Sergienko, S. Pugach, O. Dudarev, A. Charkin, A. Gukov, L. Bröder, A. Andersson, E. Spivak, N. Shakhova // Nature Geoscience. - 2016. - V. 9. - P. 361-365.

3. Deglacial mobilization of pre-aged terrestrial carbon from degrading permafrost / M. Winterfeld, G. Mollenhauer W. Dummann, P. Kohler, L. Lembke-Jene, V.D. Meyer, J. Hefter, C. Mclntyre, L. Wacker, U. Kokfelt, R. Tiedemann // Nature Communications. -2018 . - V. 9. -3666.

4. Rapid $\mathrm{CO} 2$ release from eroding permafrost in seawater G. Tanski, D. Wagner, C. Knoblauch, M. Fritz, T. Sachs, H. Lantuit // Geophysical Research Letters. - 2019. - V. 46. № 20. - P. 11244-11252.

5. Insights from Rock-Eval analysis on the influence of sample weight on hydrocarbon generation from Lower Permian organic matter rich rocks, West Bokaro basin, India / B. Hazra, C.Ö. Karacan, D.M. Tiwari, P.K. Singh, A.K. Singh // Marine and Petroleum Geology. - 2019. - V. 106. - P. 160-170. исследуемых образцах варьируется в пределах от 0,40 до 2,73 \%, при этом доля пиролизуемого углерода в общем объеме ТОС составляет от 20 до $30 \%$. В целом определяющий вклад в состав органического вещества вносят наземные источники осадочного материала: речной сток и береговая эрозия. В работе предпринята попытка разделить пиролитические подписи этих двух источников. Предварительные результаты указывают на возможность такого разделения на основе значений водородного (НI) и кислородного индексов (OI) и температуры Tpeak.

Для осадков также определено пороговое значение водородного индекса (НI=130 мг УВ/г Сорг), которое можно отнести к переходному значению преобладания морского или наземного источников в составе OB для данного района работ.

Зависимость содержания кислородсодержащих структур (S3) и доли пелитовой фракции дает основание предположить, что повторяющееся ресуспендирование осадка регулярно подвергает окислению ассоциированное с матрицей зерен ОВ. Таким образом, тезис о ведущей роли минеральной матрицы в обеспечении сохранности ОВ при латеральном переносе в системе суша-шельф моря Лаптевых требует дополнительных исследований.

Работа (постановка иели и задач, пробоподготовка, проведение пиролитического анализа, интерпретация результатов) выполнена при финансовой поддержке РНФ (грант № 19-77-00067). Гранулометрический анализ образиов был выполнен при поддержке гранта РФФИ №20-05-00545. Отбор проб в 2018-2019 г2. проводился при частичной поддержке гранта РНФ №18-77-10004. Авторы выражают глубокую благодарность профессору Ивану Васильевичу Гончарову за постановку геохимических методов работы с современными осадками в Международной научно-образовательной лаборатории арктических морей Томского политехнического университета, а также ценные замечания и рекомендации при подготовке данной работьл.

6. Correlation of zooclast reflectance with Rock-Eval Tmax values within Upper Ordovician Cape Phillips Formation, a potential petroleum source rock from the Canadian Arctic Islands / D.P. Synnott, K. Dewing, O.H. Ardakani, M. Obermajer // Fuel. 2018. - V. 2271. - P. 165-176.

7. Correlating Rock-Eval ${ }^{\mathrm{TM}} \mathrm{Tmax}$ with bitumen reflectance from organic petrology in the Bakken Formation / A. Abarghani, M. Ostadhassan, T. Gentzis, H. Carvajal-Ortiz, S. Ocubalidet, B. Bubach, M. Mann, X. Hou // International Journal of Coal Geology. - 2019. - V. 205. - P. 87-104.

8. Evaluating the total oil yield using a single routine Rock-Eval experiment on as-received shales / J. Li, M. Wang, Z. Chen, S. Lu, C. Jiang, G. Chen, S. Tian // Journal of Analytical and Applied Pyrolysis. - 2019. - V. 144. - 104707

9. Soil organic matter (SOM) characterization by Rock-Eval pyrolysis: scope and limitation / J.R. Disnar, B. Guillet, D. Keravis, C. Di Giovanni, D. Sebag // Organic Geochemistry. - 2003. V. 34 - P. 327-343.

10. Monitoring organic matter dynamics in soil profiles by 'Rock Eval pyrolysis': bulk characterization and quantification of degradation / D. Sebag, J.R. Disnar, B. Guillet, C. Di Giovanni, E.P. Verrecchia, A. Durand // European Journal of Soil Science. - 2006. - V. 57. P. 344-355.

11. Диагенетическая трансформация органического вещества голоценовых осадков Черного моря по данным пиролиза / 
В.Н. Меленевский, С.В. Сараев, Е.А. Костырева, В.А. Каширцев // Геология и геофизика. - 2017. - Т. 58. - № 2. - С. 273-289.

12. Меленевский В.Н., Леонова Г.А., Конышев А.С. Результаты исследования органического вещества современных осадков озера Белое (Западная Сибирь) по данным пиролитических методов // Геология и геофизика. - 2011. - Т. 52. - № 6. C. $751-762$.

13. Liebezeit G., Wiesner M.G. Pyrolysis of recent marine sediments // I. Biopolymers. Advances in Organic Geochemistry. - 1990. V. 16. - P. 1179-1185.

14. Marchand C., Lallier-Vergus E., Baltzer F. The composition of sedimentary organic matter in relation to the dynamic features of a mangrove-fringed coast in French Guiana // Estuarine. Coastal and Shelf Science. - 2003. - V. 56. - P. 119-130.

15. Семилетов И.П. Разрушение мерзлых пород побережья как важный фактор в биогеохимии шельфовых вод Арктики // Доклады Академии наук. - 1999. - Т. 368. - № 5. - С. 679-682.

16. Coastal erosion vs riverine sediment discharge in the Arctic Shelf seas / V. Rachold, M.N. Grigoriev, F.E. Are, S.C. Solomon, E. Reimnitz, H. Kassens, M. Antonow // International Journal of Earth Sciences. - 2000. - V. 89. - P. 450-459.

17. Proshutinsky A.Y., Johnson M.A. Two circulation regimes of the wind-driven Arctic Ocean // Journal Geophysical Research. 1997. - V. 102. - P. 12493-12514.

18. Stein R., Fahl K. The Laptev Sea: distribution, sources, variability and burial of organic carbon // The Organic Carbon Cycle in the Arctic Ocean / Ed. by R. Stein, R.W. Macdonald. - Berlin: Springer-Verlag, 2004. - P. 213-236.

19. Carrie J., Sanei H., Stern G. Standardisation of Rock-Eva pyrolysis for the analysis of recent sediments and soils // Organic Geochemistry. - 2013. - V. 46. - P. 38-53.

20. Rock-Eval 6 technology: performances and developments / F. Behar, B. Beaumont, B. De, H.L. Penteado // Oil \& Gas Science and Technology. Revue IFP. - 2001. - V. 56. - P. 111-134.

21. Литологические особенности донных осадков и их влияние на распределение органического материала на территории Восточно-Сибирского шельфа / Е. Панова, А.Рубан., О. Дударев, Т. Тези, Л. Брёдер, О. Густафссон, А. Гринько, Н. Шахова, И. Гончаров, А. Мазуров, И. Семилетов // Известия Томского политехнического университета. Инжиниринг георесурсов. 2017. - T. 328. - № 8. - C. 94-105.

22. Лихт Ф.Р., Астахов А.С., Боцул А.И. Структура осадков и фации Японского моря. - Владивосток: Изд-во ДВНЦ АН CCCP, 1983. $-283 \mathrm{c}$.

23. Shepard F.P. Nomenclature based on sand-silt-clay ratios // Journal of Sedimentary Petrology. -1954. - V. 24 (3). - P. 151-158.

24. Organic carbon sources and transformations in mangrove sediments: a Rock-Eval pyrolysis approach / C. Marchand, E. Lallier-Vergès, J.-R. Disnar, D. Kéravis // Organic Geochemistry. - 2008. - V. 39. - C. 408-421.

25. Stein R., Boucsein B., Meyer H. Anoxia and high primary production in the Paleogene central Arctic Ocean: first detailed records from Lomonosov Ridge // Geophysical Research Letters. 2006. - V. 33. - L18606.

26. Fate of terrigenous organic matter across the Laptev Sea from the mouth of the Lena River to the deep sea of the Arctic interior / L. Bröder, T. Tesi, J. A. Salvadó, I. Semiletov, O. Dudarev, Ö. Gustafsson // Biogeosciences. - 2016. - V. 13. - P. 5003-5019.

27. Characterization of sedimentary organic matter in recent marine sediments from Hudson Bay, Canada, by Rock-Eval pyrolysis / A.A. Hare, Z.Z.A. Kuzyk, R.W. Macdonald, H. Sanei, D. Barber, G.A. Stern, F. Wang // Organic Geochemistry. - 2014. - V. 68. P. 52-60.

28. Carbon isotopes and lipid biomarker investigation of sources, transport and degradation of terrestrial organic matter in the BuorKhaya Bay, SE Laptev Sea / E.S. Karlsson, A. Charkin, O. Dudarev, I. Semiletov, J.E. Vonk, L. Sánchez-García, A. Andersson, Ö. Gustafsson // Biogeosciences. - 2011. - V. 8. P. $1865-1879$.

29. Widespread release of old carbon across the Siberian Arctic echoed by its large rivers / Ö. Gustafsson, B.E. van Dongen, J.E. Vonk, O. Dudarev, I. Semiletov // Biogeosciences. - 2011. V. 8. - P. 1737-1743.

30. Meyers P.A., Ishiwatari R. Lacustrine organic geochemistry - an overview of indicators of organic matter sources and diagenesis in lake sediments // Organic Geochemistry. - 1993. - V. 20. P. 867-900.

Поступила 03.06.2020 г.

\section{Информация об авторах}

Гершелис E.B., кандидат геолого-минералогических наук, доцент отделения геологии Инженерной школы природных ресурсов Национального исследовательского Томского политехнического университета.

Kaиanoв P.C., инженер Инженерной школы природных ресурсов Национального исследовательского Томского политехнического университета.

Pубан A.C., кандидат геолого-минералогических наук, доцент отделения геологии Инженерной школы природных ресурсов Национального исследовательского Томского политехнического университета.

Оберемок И.А., магистрант отделения геологии Инженерной школы природных ресурсов Национального исследовательского Томского политехнического университета.

Леонов A.A., инженер отделения материаловедения Инженерной школы новых производственных технологий Национального исследовательского Томского политехнического университета; младший научный сотрудник лаборатории пучково-плазменной инженерии поверхности Института сильноточной электроники СО РАН.

Черных Д.В., кандидат физико-математических наук, старший научный сотрудник лаборатории акустической океанографии, Тихоокеанского океанологического института им. В.И. Ильичева ДВО РАН.

Дударев O.B., доктор геолого-минералогических наук, главный научный сотрудник лаборатории арктических исследований Тихоокеанского океанологического института им. В.И. Ильичева ДВО РАН.

Семилетов И.П., член-корреспондент РАН, доктор географических наук, заведующий лабораторией арктических исследований Тихоокеанского океанологического института им. В.И. Ильичева ДВО РАН; профессор отделения геологии Инженерной школы природных ресурсов Национального исследовательского Томского политехнического университета. 
UDC 551.35

\section{IDENTIFYING SOURCES OF ORGANIC CARBON IN SURFACE SEDIMENTS OF LAPTEV SEA SHELF USING A ROCK-EVAL APPROACH}

Elena V. Gershelis ${ }^{1}$, elenapanova@tpu.ru

Roman S. Kashapov', kashapovrs@yandex.ru

\author{
Alexey S. Ruban ${ }^{1}$, \\ ruban@tpu.ru
}

Irina A. Oberemok ${ }^{1}$, genuine.@yandex.ru

1 National Research Tomsk Polytechnic University, 30, Lenin avenue, Tomsk, 634050, Russia.

2 Institute of High Current Electronics SB RAS, 4, Academichesky avenue, Tomsk, 634055, Russia.

3 Pacific Oceanological Institute, Russian Academy of Sciences, 43, Baltiyskaya street, Vladivostok, 690041, Russia.

\author{
Andrey A. Leonov 1,2 \\ laa91@tpu.ru
}

Denis V. Chernykh ${ }^{3}$, denis.chernykh.vl@gmail.com

\author{
Oleg V. Dudarev3, \\ dudarev@poi.dvo.ru
}

\section{Igor P. Semiletov 3,1 ,} ipsemiletov@alaska.edu

An increasing rate of degradation of coastal and subsea permafrost leads to remobilization of huge amounts of organic carbon. To know how this remobilized carbon behaves while being transported through the land-shelf system is crucially important for understanding an extremely fragile Arctic ecosystem.

This study is aimed at tracing the geochemical signals of organic matter along the profile from the coastal zone to the continental slope of the Laptev Sea, using the Rock-Eval approach. We investigated surface sediment samples obtained during the Arctic marine expeditions of 2018-2019 on the RN «Akademik Mstislav Keldysh».

The most active oxidation of organic matter, exported with river runoff and products of coastal erosion, occurs in the coastal zone at a depth of several tens of meters. A significant effect on the organic matter composition is exerted by the sediment export from Novosibirsk Islands eroding coastlines. We assume that various products carried by river runoff and coastal erosion are characterized by various signatures detected by the Rock-Eval method (e.g., the Ol and Tpeak values). It is also shown that the mineral matrix does not seem to provide a first-order control on preventing organic matter degradation during transport from the coastal zone to deep-sea basins.

\section{Key words:}

Pyrolysis, bottom sediments, organic matter, hydrocarbons, Arctic, Laptev Sea.

The research (goal setting, sample preparation, pyrolitic analysis, interpretation of results) was financially supported by the RSF (grant no. 19-77-00067). Grain size analysis was supported by the RFBR grant no. 20-05-00545. Sampling during Arctic expeditions in 2018-2019 was partially supported by the RSF (grant no. 18-77-10004). The authors express deep appreciation to professor Ivan V. Goncharov for development of geochemical methods at the International laboratory of Arctic seas at Tomsk Polytechnic University as well as for his valuable comments and recommendations on this paper.

\section{REFERENCES}

1. Vonk J.E., Sánchez-García L., Van Dongen B.E., Alling V., Kosmach D., Charkin A., Semiletov I.P., Dudarev O.V., Shakhova N., Roos P., Eglinton T.I., Andersson A., Gustafsson Ö. Activation of old carbon by erosion of coastal and subsea permafrost in Arctic Siberia. Nature, 2012, vol. 489, pp. 137-140.

2. Semiletov I., Pipko I., Gustafsson Ö., Anderson L.G., Sergienko V., Pugach S., Dudarev O., Charkin A., Gukov A., Bröder L., Andersson A., Spivak E., Shakhova N. Acidification of East Siberian Arctic Shelf waters through addition of freshwater and terrestrial carbon. Nature Geoscience, 2016, vol. 9, pp. 361-365.

3. Winterfeld, M., Mollenhauer, G., Dummann, W., Kohler P., Lembke-Jene L., Meyer V. D., Hefter J., Mclntyre C., Wacker L., Kokfelt U., Tiedemann R. Deglacial mobilization of pre-aged terrestrial carbon from degrading permafrost. Nature Communications, 2018, vol. 9, 3666.

4. Tanski G., Wagner D., Knoblauch C., Fritz M., Sachs T., Lantuit H. Rapid $\mathrm{CO} 2$ release from eroding permafrost in seawater. Geophysical Research Letters, 2019, vol. 46, no. 20, pp. 11244-11252.

5. Hazra B., Karacan C.Ö., Tiwari D.M., Singh P.K., Singh A.K. Insights from Rock-Eval analysis on the influence of sample weight on hydrocarbon generation from Lower Permian organic matter rich rocks, West Bokaro basin, India. Marine and Petroleum Geology, 2019, vol. 106, pp. 160-170.

6. Synnott D.P., Dewing K., Ardakani O.H., Obermajer M. Correlation of zooclast reflectance with Rock-Eval Tmax values within Upper Ordovician Cape Phillips Formation, a potential petroleum source rock from the Canadian Arctic Islands. Fuel, 2018, vol. 2271, pp. 165-176.

7. Abarghani A., Ostadhassan M., Gentzis T., Carvajal-Ortiz H., Ocubalidet S., Bubach B., Mann M., Hou X. Correlating RockEval $^{\text {TM }}$ Tmax with bitumen reflectance from organic petrology in the Bakken Formation. International Journal of Coal Geology, 2019, vol. 205, pp. 87-104.

8. Li J., Wang M., Chen Z., Lu S., Jiang C., Chen G., Tian S. Evaluating the total oil yield using a single routine Rock-Eval experiment on as-received shales. Journal of Analytical and Applied Pyrolysis, 2019, vol. 144, 104707.

9. Disnar J.-R., Guillet B., Keravis D., Di Giovanni C., Sebag D. Soil organic matter (SOM) characterization by Rock-Eval pyrolysis: scope and limitation. Organic Geochemistry, 2003, vol. 34, pp. 327-343. 
10. Sebag D., Disnar J.-R., Guillet B., Di Giovanni C., Verrecchia E.P., Durand A. Monitoring organic matter dynamics in soil profiles by 'Rock-Eval pyrolysis': bulk characterization and quantification of degradation. European Journal of Soil Science, 2006, vol. 57, pp. 344-355.

11. Melenevskii V.N., Saraev S.V., Kostyreva E.A., Kashirtsev V.A. Diagenetic transformation of organic matter of the Holocene Black sea sediments according to pyrolysis data. Geology and Geophysics, 2017, vol. 58, no. 2, pp. 273-289. In Rus.

12. Melenevskii V.N., Leonova G.A., Konyshev A.S. The organic matter of the recent sediments of lake Beloe. Geology and Geophysics, 2011, vol. 52, no. 6, pp. 751-762. In Rus.

13. Liebezeit G., Wiesner M.G. Pyrolysis of recent marine sediments. I. Biopolymers. Advances in Organic Geochemistry, 1990, vol. 16, pp. $1179-1185$.

14. Marchand C., Lallier-Vergus E., Baltzer. F. The composition of sedimentary organic matter in relation to the dynamic features of a mangrove-fringed coast in French Guiana. Estuarine. Coastal and Shelf Science, 2003, vol. 56, p. 119-130.

15. Semiletov I.P. Destruction of the coastal permafrost ground as an important factor in biogeochemistry of the Arctic Shelf waters. Doklady Russian Academy Sciences, 1999, vol. 368, pp. 679-682. In Rus.

16. Rachold V., Grigoriev M.N., Are F.E., Solomon S., Reimnitz E. Kassens H., M. Antonow. Coastal erosion vs riverine sediment discharge in the Arctic Shelf seas. International Journal of Earth Sciences, 2000, vol. 89, pp. 450-459.

17. Proshutinsky A.Y., Johnson M.A. Two circulation regimes of the wind-driven Arctic Ocean. Journal Geophysical Research, 1997, vol. 102, pp. 12493-12514.

18. Stein R., Fahl K. The Laptev Sea: distribution, sources, variability and burial of organic carbon. The Organic Carbon Cycle in the Arctic Ocean. Eds. R. Stein, R.W. Macdonald. Berlin, SpringerVerlag, 2004, pp. 213-236.

19. Carrie J., Sanei H., Stern G. Standardisation of Rock-Eval pyrolysis for the analysis of recent sediments and soils. Organic Geochemistry, 2013, vol. 46, pp. 38-53.

20. Behar F., Beaumont B., De B., Penteado H.L. Rock-Eval 6 technology: performances and developments. Oil \& Gas Science and Technology, Revue IFP, 2001, vol. 56, pp. 111-134.

21. Panova E., Ruban A., Dudarev O., Tesi T., Bröder L., Gustafsson O., Grinko A., Shakhova N., Goncharov I., Mazurov A., Semiletov I.
Lithological features of surface sediment and their influence on organic matter distribution across the East-Siberian arctic shelf. Bulletin of the Tomsk Polytechnic University. Geo Assets Engineering, 2017, vol. 328, no. 8, pp. 94-105. In Rus.

22. Likht F.R. Struktura osadkov i fatsii Yaponskogo moray [Sediment structure and facies of Japan Sea]. Vladivostok, Far East Research Center Publ., 1983. 283 p.

23. Shepard F.P. Nomenclature based on sand-silt-clay ratios. Journal of Sedimentary Petrology, 1954, vol. 24, no. 3, pp. 151-158.

24. Marchand C., Lallier-Vergès E., Disnar J.-R., Kéravis D. Organic carbon sources and transformations in mangrove sediments: a Rock-Eval pyrolysis approach. Organic Geochemistry, 2008, vol. 39 , pp. 408-421.

25. Stein R., Boucsein B., Meyer H. Anoxia and high primary production in the Paleogene central Arctic Ocean: first detailed records from Lomonosov Ridge. Geophysical Research Letters, 2006, vol. 33, L18606.

26. Bröder L., Tesi T., Salvadó J.A., Semiletov I.P., Dudarev O.V., Gustafsson Ö. Fate of terrigenous organic matter across the Laptev Sea from the mouth of the Lena River to the deep sea of the Arctic interior. Biogeosciences, 2016, vol. 13, pp. 5003-5019.

27. Hare A.A., Kuzyk Z.Z.A., Macdonald R.W., Sanei H., Barber D., Stern G.A., Wang F. Characterization of sedimentary organic matter in recent marine sediments from Hudson Bay, Canada, by Rock-Eval pyrolysis. Organic Geochemistry, 2014, vol. 68, pp. 52-60.

28. Karlsson E.S., Charkin A., Dudarev O., Semiletov I., Vonk J.E., Sánchez-García L., Andersson A., Gustafsson Ö. Carbon isotopes and lipid biomarker investigation of sources, transport and degradation of terrestrial organic matter in the Buor-Khaya Bay, SE Laptev Sea. Biogeosciences, 2011, vol. 8, pp. 1865-1879.

29. Gustafsson O., Van Dongen B.E., Vonk J.E., Dudarev O.V., Semiletov I.P. Widespread release of old carbon across the Siberian Arctic echoed by its large rivers. Biogeosciences, 2011, vol. 8, pp. 1737-1743.

30. Meyers P.A., Ishiwatari R. Lacustrine organic geochemistry - an overview of indicators of organic matter sources and diagenesis in lake sediments. Organic Geochemistry, 1993, vol. 20, pp. 867-900.

Received: 3 June 2020.

\section{Information about the authors}

Elena V. Gershelis, Cand. Sc., associate professor, National Research Tomsk Polytechnic University.

Roman S. Kashapov, engineer, National Research Tomsk Polytechnic University.

Alexey S. Ruban, Cand. Sc., associate professor, National Research Tomsk Polytechnic University.

Irina A. Oberemok, master-student, National Research Tomsk Polytechnic University.

Andrey A. Leonov, engineer, National Research Tomsk Polytechnic University; junior researcher, Institute of High Current Electronics SB RAS.

Denis V. Chernykh, Cand. Sc., senior researcher, Pacific Oceanological Institute, Russian Academy of Sciences.

Oleg V. Dudarev, Dr. Sc., leading researcher, Pacific Oceanological Institute, Russian Academy of Sciences.

Igor P. Semiletov, corresponding member of the RAS, Dr. Sc., head of the laboratory, Pacific Oceanological Institute, Russian Academy of Sciences; professor, National Research Tomsk Polytechnic University. 